tific Libraries of To-day" is a valuable guide to the libraries of Great Britain.

This learned and laborious work will be of great use both to librarians and to students of the history of science. When a new edition is called for, no doubt certain omissions, including those to which passing reference has been made and others that have been noted, will be remedied. A citation of English translations, where they exist, of works in foreign tongues might be well. A desirable addition would be a list of the Latin names given to cities in Latin editions of the seventeenth and eighteenth centuries. There are frequent references in this book to editions at "Geneva and also Coloniae Allobrogorum", but Geneva and Colonia Allobrogorum are the same place. It is pleasant to be able to end this notice not with the reviewer's customary complaint of an inadequate index, but with grateful acknowledgment of a full and excellent one, which adds to the value of the book.

E. N. DA C. ANDrade

\section{A REFERENCE WORK OF HYDRAULIC ENGINEERING}

Irrigation and Hydraulic Design

By Dr. Serge Leliavsky. Vol. 1 : General Principles of Hydraulic Design. Pp. xiii $+492+13$ plates. (London : Chapman and Hall, Ltd., 1955.) 126s. net.

$\mathrm{T}$ HIS book is the first of three volumes dealing with the problems of irrigation engineering, and sets out the basic principles of design founded on the author's considerable experience of irrigation and hydroelectric systems of the Dnieper and Nile. The book is intended as a work of reference, and its length and the historical treatment adhered to throughout certainly preclude its use as a handbook.

The book is divided into three chapters. The first treats problems of flow through a pervious soil, as they affect the design of hydraulic structures. Starting from the basic concepts of flow in a homogeneous, porous medium, the author passes to discussions of uplift pressures, potential flow and the analytical methods of computing flow nets and base pressures for various foundation arrangements. This section, which is treated most exhaustively, is followed by a treatment of graphical and experimental methods for determining the flow net, approximate calculation by the method of independent variables, percolation in non-homogeneous soils, piping and finally percolation through earth embankments. In view of the limitation of the analytical methods to foundations, in which the geometry is fairly simple, more space might with advantage have been devoted to the more general, if less precise, methods.

The arrangement of the discussion of the theories of piping and uplift pressure is rather confusing. The Bligh creep-head theory is presented together with the earlier Terzaghi liquefaction theory, while Lane's weighted creep theory is reserved for a later section. Although he states that Lane's theory is but an extension of the earlier Bligh theory, the author fails to warn the reader of the dangers of their application to design. Modern practice in soil mechanics only admits the application of empirical design procedures when a more rational scientific approach is not available. Methods based on averago soil coefficients must always be treated with suspicion. Also, the general problem of atability of weirs and failure due to shearing of the subsoil under conditions of upward seepage has unfortunately not been touched; neither has the potential instability at the toe due to vibration of the apron.

The second chapter deals with design methods for preventing or reducing scour downstream of hydraulic works. Early designs relied largely on a protecting apron downstream, and formulæ for the extent of the apron and the depth of scour to be expected were produced by Bligh and Khosla from an examination of existing weirs in India. The author shows that data for the depth of scour downstream of several barrages on the Nile confirm Khosla's findings, despite the approximate nature of the coefficients used. Later designs have been based almost exclusively on tests made with small-scale models, and a discussion. of the underlying principles and the results occupies a large part of the chapter. As far as the motion of the water is concerned, the guiding principle of such tests is the conservation of the Froude number; but the parameter which controls the movement of bed material, and so is of paramount importance when relating scour in model and full scale, has not yet been settled. The author mentions the conflicting views of various authorities on the subject, without coming to any definite conclusion.

Apart from this question, models have been useful in revealing the flow patterns likely to occur in specific designs and have contributed largely to an understanding of the methods by which the standing wave can be used to reduce scour. One of the latest developments of this work referred to in the chapter is the production of a set of rules for the design of stilling basins to dissipate energy behind the wave in as short a distance as possible.

The last chapter consists of two sections. The first deals with uniform flow and traces the historical development of the subject from the early ideas of Galileo to the modern advances of Prandtl and his collaborators. The latter have succeeded in placing the subject on a rational basis, and the forms of the friction formulæ so deduced are rapidly supplanting the earlier purely empirical formulæ of Bazin, Ganguillet-Kutter and Manning. The second section is taken up with steady non-uniform flow and gives in considerable detail the various methods which have been used for integrating the basic flow equations, together with complete numerical tables and charts for their application.

The book is well illustrated and lucidly written and includes a good supply of references.

\section{ASPECTS OF THE ANIMAL CELL}

\section{International Review of Cytology}

Vol. 3. Edited by G. H. Bourne and J. F. Danielli. Pp. $x+530$. (London: Academic Books, Ltd.; New York: Academio Press, Ino., 1954.) 9.50 dollars; $76 \mathrm{~s}$.

THE thirteen articles which make up the third "International Review of Cytology" have in common a concern with some aspect or other of contemporary cell biology, the technical quality of their production, and the price one must pay to possess one or more of them. The first needs no comment, the second is good, and the third, by present-day standards, is not excessive. For the rest, each article should, but in a short space cannot, be treated separately on its merits. It would not be 